\title{
My Call on COVID Duty: An Experience of a Nurse Teacher
}

\author{
Chris Thomas
}

\begin{abstract}
COVID-19 outbreak brought all the health personnel together to serve the community. Like so many health workers around the world, nurses too were called to the battlefront. I being a nursing teacher express my first experience during COVID duty, which was a challenging task, yet it helped me to build my capacity and competencies.

Keywords: COVID-19, Health personnel, Nurses, Nursing teacher.

Pondicherry Journal of Nursing (2021): 10.5005/jp-journals-10084-13114
\end{abstract}

\section{"Unfortunately there is always a first time for everything! Good or Bad"}

"It was like something out of a nightmare," nursing teaching faculties from Nursing College deputed as clinical nurse in COVID ward (during the second wave of COVID, month of May-June, 2021). Being a psychiatry nurse teacher, it was a landmark change for me.

Strange speculations ran in my mind, the time when the Board of Management of our hospital decided to depute their teaching faculties to their parent hospital as a clinical nurse at COVID unit. My primary concern before stepping into the hospital was, "What can I, a psychiatry nursing teacher who is not in routine bedside nursing, actually do to help?" The answer proved to be rather a lot.

It was like a role transition crisis (nurse teacher to bedside nursing) for me from one capacity to other though the duty period was for only one full month. Yes, being a nurse I should not separate clinic and academic. We must be ready to take up any roles and responsibilities belong to nursing profession. Perhaps, the struggles and tribulations everyone had during the second wave of coronavirus, it genuinely lost the momentum. I cannot express in words the physical and emotional trauma I have witnessed during this short period. I was dealing with personal troubles in addition to working extremely for long hours in new settings with viral exposure. I'm a diabetic with renal calculi who is concerned about COVID comorbidities. I had to part with my 3-year-old kid and my wife to my native state for a long period of time.

I could choose to not work in any situation. Excessive thoughts ran through my mind like anticipatory anxiety about health, family, friends, working atmosphere, and so on; my family members were also shaken by the news. In state of dilemma, later I decided to volunteer with my other two colleagues (Mr Maneesh Kumar Sharma and Ms Sudhanjali) as there was clinical nurse's deficiency at our hospital. Management agreed to provide a separate group accommodation to stay after COVID duty hours. Food was taken care by them; I must appreciate the management, even though I was unable to request special diabetic food for me because the patients were our top priority. At the beginning in the hospital, I was counting every minute; it was like a war against time.

The first day was very terrific, a morning duty ( 8 hours), wore very heavy personal protective equipment (PPE) kit, felt like astronaut in lovely Earth or else like human robots, could see numerous astronauts in PPE suits rushing around. Oh My God! I could not resist the heat of the PPE kit that included face shield, double head caps, double masks, double gloves, full layer gown,
Department of Psychiatry Nursing, Saroj Lalji Mehrotra Global Nursing College, Global Hospital and Research Centre, Sirohi, Rajasthan, India

Corresponding Author: Chris Thomas, Associate Professor, Department of Psychiatry Nursing, Saroj Lalji Mehrotra Global Nursing College, Global Hospital and Research Centre, Sirohi, Rajasthan, India, e-mail: christhomas0002@yahoo.com

How to cite this article: Thomas C. My Call on COVID Duty: An Experience of a Nurse Teacher. Pon J Nurs 2021;14(3):71-72.

Source of support: Nil

Conflict of interest: None

and shoe cover. I realized that it will be a great task for me and it was not my cup of tea. I was dehydrated, my nose got hurt, I was sweating profusely all over my body, and it was ill-time for me. After 3 days, I got adapted to my additional outfit. Working with 1:10-1:12 ratio was not simple at the initial period of battle. Wrapped up in PPE kit could hardly identify each other, I wrote my name on the PPE kit. Patients were looking at us as a stranger; they could not see our smiles behind the masks. I'd never seen patients suffocate and die in this way before. The worst part is witnessing patient's death, and they are dying alone without the presence of their loved ones. We want to touch them with bare hand but controlled our sentiments. Seeing patient's mental agony was another challenge where clients felt they had lost their human connection, watching other co-patients distress, cannot talk to their family members, anticipating about their daily reports, seeking discharge and were curious about the aftereffects, etc. I was overwhelmed with stress even after duty hours, could not able to overcome the physical and mental burden for several days. I could able to follow and practice standard protective measures, which were learned through different online sessions, modular trainings, webinars, and reading articles in the past year. I am grateful to our hospital for providing us PPE kit and other standard precautions without any hassles. This is one of the reasons I am safe even after my duties.

Bonding we created among each health team member was amazing amid the stress. Clinical nurses' support was a great help in few clinical procedures. I recalled each of the patients for whom I was responsible. It was difficult to provide complete nursing care to all patients, in fact with teamwork; we were able

(0) The Author(s). 2021 Open Access This article is distributed under the terms of the Creative Commons Attribution 4.0 International License (https://creativecommons [2]. org/licenses/by-nc/4.0/), which permits unrestricted use, distribution, and non-commercial reproduction in any medium, provided you give appropriate credit to the original author(s) and the source, provide a link to the Creative Commons license, and indicate if changes were made. The Creative Commons Public Domain Dedication waiver (http://creativecommons.org/publicdomain/zero/1.0/[3]) applies to the data made available in this article, unless otherwise stated. 
to provide maximum benefits to patients. Treatment regimen in my ward was similar for almost all the patients, irrespective of any complications and comorbidities. COVID-19 pandemic handling needs both iron hand and compassionate heart. After a long gap of my postgraduation, I was able to do numerous blood collections, IV insertions, swabbing, suctioning, feeding, medication administration (via central line, infusion pump), oxygen administration in various kinds of masks, patient positioning, frequent oxygen saturation monitoring, maintaining intake/output charts, ECG checking, understanding patients monitors, admission and discharge procedures, application of nursing process based on various assessments, application of critical thinking, post-COVID awareness including vaccination and weaning patients off oxygen gave a heavy sigh of relief and many more.

My pharmacology knowledge strengthened my critical thinking skills and helped me to understand the pharmacodynamics and assisted me in collaborating with intern doctors to taper the dose and stop the drug when adverse reactions were observed (e.g., discontinuing low-molecular-weight heparin when patient had bloody stool). These may appear to be basic, yet they helped me reshape my clinical skills. Aside from routine nursing procedures and treatment regimens, few yoga sessions, meditation classes, breathing and coughing exercises, recreational activities (dancing, singing, action songs), telecounseling, individual counseling, gratitude training, motivational enhancement for mild and moderate patients as well as mental health awareness proved to be extremely beneficial. Despite our team's efforts, we lost a number of patients, especially young ones who were in poor health. However, we had a number of patients who had fought COVID-19 and succeeded, which gave us hopes. I still remember the way patients express their gratitude with tears in their eyes when got cured. These are not small things, but it has a significant impact on my mental health while caring for the patients. My confidence in practical abilities as well as communication with different kinds of patients and staff has improved. If I could do this much as a nursing faculty regardless of my specialty, imagine how astounding and incredible clinical nurses' contributions to health care would be.

My personal observation is that in India holistic nursing care is inevitable in caring COVID patients and others, ${ }^{1}$ employing adequate number of clinical nurses to reduce the workload and work hours, ${ }^{2}$ training more nurses to improve preparedness to combat COVID-19 or any other pandemic ${ }^{3}$ (possibly through mandatory training modules), need of strong clinical nursing leadership at the hospital, recruiting critical care nurses/nurse practitioners, introducing preceptorship program to adapt new role, ${ }^{4}$ need to have a robust system of employing qualified nurses at the hospital to ensure that nurses are enough competent to practice, health insurance for all employees at the hospital by employer, improving financial security for the nurses like their salary could be raised to $60-75 \%$ of that of the doctors based on the experience, nurses empowerment must be addressed like including nurses in the hospital policymaking, intermittent guidance and counseling services to frontline nursing warriors and evidence-based nursing care will work out. Many more can be done to strengthen nursing care in COVID-19 context. It is the need of the hour to improve the quality of nursing education in every nursing college and school, need to stop non-attending nursing courses, especially postgraduation. It is the responsibility of every individual nursing leader to abolish these least quality practices so that professional integrity can be maintained. Hence, we can vision a better nursing world in India.

The challenges are not yet gone. COVID-19 provided us with an opportunity to learn more about the profession and understand the essence of nursing care. Nurses' contribution to the society's health will be recognized in perpetuity; thus, we require a secure system that allows nurses to feel more confident in their skills to deliver efficient nursing care to the patients on a regular basis.

\section{A Word of Gratitude}

My heartfelt gratitude to the hospital management, nursing team, healthcare workers, cherished patients, their families, other departments, and of course my loving colleagues Mr Maneesh Kumar Sharma (Assistant Professor) and Ms Sudhanjali (Lecturer) and other colleagues as well for their unwavering support.

\section{OrCID}

Chris Thomas ㄴ https://orcid.org/0000-0001-8273-147X

\section{References}

1. Wang H, Zeng T, Wu X, Sun H. Holistic care for patients with severe coronavirus disease 2019: an expert consensus. Int J Nurs Sci 2020;7(2):128-134. DOI: 10.1016/j.ijnss.2020.03.010. PMID: 32292634; PMCID: PMC712866.

2. Anton N, Hornbeck T, Modlin S, Haque MM, Crites M, Yu D. Identifying factors that nurses consider in the decision-making process related to patient care during the COVID-19 pandemic. PLoS One 2021;16(7):e0254077. DOI: 10.1371/journal.pone.0254077.

3. Al Thobaity A, Alshammari F. Nurses on the frontline against the COVID-19 pandemic: an integrative review. Dubai Med J 2020;3(3):87-92. DOI: 10.1159/000509361.

4. Thomas C. Preceptorship model to bridge the gap between nursing theory and practice, vol.4.4. Centre of Continuing Nursing Excellence (CCNE) Digest, CCNE Publishers; 2019. Available from: http://nursing. celnet.in/wp-content/uploads/2019/07/4.pdf. 